\title{
DIETAS SIMPLES E COMPLEXA SOBRE O DESEMPENHO DE LEITÕES NA FASE DE CRECHE ${ }^{1}$
}

\author{
SIMPLE AND COMPLEX DIETS ON THE PIGLETS PERFORMANCE
}

\author{
Arlei Rodrigues Bonet Quadros ${ }^{2}$ Charles Kiefer $^{3}$ João Dionísio Henn ${ }^{4}$ \\ Geraldo Scariot $^{5}$ José Henrique Souza da Silva $^{6}$
}

\section{RESUMO}

O objetivo deste trabalho foi avaliar o desempenho de leitões, dos 21 aos 63 dias de idade, alimentados com dietas simples ou complexas. Foram utilizados noventa e seis leitões tricross, sendo alimentados à vontade. $O$ delineamento experimental foi o inteiramente casualizado, com 2 tratamentos $e$ 12 repetições. $O$ consumo diário de ração $(C D R)$, ganho diário de peso (GDP), a conversão alimentar (CA) e o peso foram avaliados no período. Os leitões alimentados com dietas complexas apresentaram maior CDR e maior GDP, no pós desmame. $O$ tipo de dieta não influenciou o peso e a CA dos leitões na fase de creche.

Palavras-chave: dietas simples, dietas complexas, leitões, nutrição.

\section{SUMMARY}

The objective of this work was to evaluate diets fed from 21 to 63 days of age on piglets performance. Ninety-six piglets three crossbrad were fed with two types of diets: simple and complex. A completely randomized design with two treatments and twelwe replicates per treatment was used. The daily feed intake (DFI), the daily weight gain (DWG), the feed:gain ratio $(F: G)$ and the weights were evaluated in the period. The piglets fed with complex diets had higher DFI and $D W G$ in the post lactation. In the period (nursery phase), there was no diet type effect on weight and the $F: G$.

Key words: simple diets, complex diets, piglets, nutrition.

\section{INTRODUÇÃO}

Ao contrário do que ocorre em condições naturais, quando o desmame é um processo gradual, sem mudanças dramáticas no trato gastrintestinal, o desmame precoce é um dos momentos mais críticos para os leitões. Vários fatores causadores de estresse, como a separação da mãe, mudança de ambiente, deficiência no controle ambiental, dificuldades de adaptação a comedouros e bebedouros, mistura com leitões de outras leitegadas e a troca de dieta, levam à queda da imunidade e redução do consumo, favorecendo a manifestação de doenças e reduzindo a taxa de crescimento.

No momento do desmame ocorre mudança brusca no tipo de dieta, e o leitão é forçado a adaptar-se rapidamente ao consumo de um alimento seco, com um novo padrão de apreensão do alimento. A gordura do leite e a lactose, principais fontes de energia durante a fase de aleitamento, são substituídas por amido e óleo vegetal. A caseína, altamente digestível, é substituída por proteínas vegetais menos digestíveis. A nova dieta também apresenta antígenos que provocam reações de hipersensibilidade transitória no intestino, além de haver a perda da proteção imunológica passiva do leite (LUDKE $\boldsymbol{e t}$ al., 1998). Dessa forma, com a

\footnotetext{
${ }^{1}$ Pesquisa financiada pelo PIBIC/CNPq, Frigorífico Prenda e Departamento de Zootecnia (DZ), Centro de Ciências Rurais (CCR), Universidade Federal de Santa Maria (UFSM).

${ }^{2}$ Zootecnista, Mestre, Professor Assistente, DZ,UFSM, 97105-900, Santa Maria. E-mail: aquadros@ccr.ufsm.br. Autor para correspondência.

${ }^{3}$ Acadêmico do Curso de Zootecnia, bolsista do PIBIC/CNPq, UFSM.

${ }^{4}$ Zootecnista.

${ }^{5}$ Acadêmico do Curso de Medicina Veterinária, UFSM

${ }^{6}$ Engenheiro Agrônomo, PhD., Professor Adjunto, DZ,UFSM.
} 
constante redução da idade de desmame, a formulação de dietas adequadas, bem como a definição de um manejo de alimentação que proporcione bom desempenho, com um custo compatível com a atividade suinícola torna-se imprescindível.

Segundo MAHAN \& LEPINE (1991), para os leitões desmamados com três semanas de idade ou mais, uma alimentação pré-desmame altamente digerível e consumida em quantidade adequada aumentará o peso ao desmame e isso se refletir em redução da idade de abate. Para minimizar os problemas de má absorção e de proliferação microbiana no intestino dos leitões recém-desmamados e para maximizar o desempenho, é necessário fornecer-lhe dietas de desmame com alta digestibilidade e baixos níveis de antígenos dietéticos. MAHAN \& CERA (1993) definem que a principal causa da redução do crescimento após o desmame resulta da redução na absorção de nutrientes e confirmam a necessidade de dieta que contenha ingredientes altamente digestíveis durante o período imediatamente posterior ao desmame. Para formular uma dieta de transição, fornecida durante a fase de aleitamento até alguns dias após o desmame, deve-se levar em conta que o leite da porca, principal dieta dos leitões até então, apresenta alto conteúdo de gordura, de lactose e de aminoácidos essenciais, todos altamente digestíveis.

Quando se compara o fornecimento de dietas simples ou dietas complexas nesse período, pode-se observar que não ocorre crescimento compensatório e que o desempenho dos leitões até a idade de abate é superior quando recebem dieta altamente digestível logo após o desmame, comparado com uma dieta simples de milho e farelo de soja (DRITZ et al., 1994). Segundo o mesmo autor, as dietas complexas são adequadas para unidades de produção intensivamente manejadas, nas quais é importante maximizar o número de animais que ocupam a mesma instalação por ano. Nesse caso, para reduzir o custo da alimentação, deve-se fornecer as dietas complexas pelo menor período de tempo possível, trocando-se por outra menos complexa em média a cada 14 dias, até o final da fase de creche. Com relação às dietas simples, a vantagem é o baixo custo e a reduzida necessidade de manejo. A desvantagem é o atraso no crescimento após o desmame, que se prolonga até o abate.

Constatam-se muitas dúvidas a respeito da melhor dieta a ser adotada para leitões na fase de creche, tornando-se, portanto, necessário realizar estudos com diferentes dietas. Por isso, propôs-se estudar o efeito do uso de dietas simples e complexas, para avaliar o desempenho de leitões na fase de creche.

\section{MATERIAL E MÉTODOS}

O experimento foi realizado no Setor de Suinocultura do Departamento de Zootecnia da Universidade Federal de Santa Maria (UFSM), Santa Maria, RS, no período de 7 de setembro a 19 de outubro de 1999. Foram utilizados 96 leitões, geneticamente similares, obtidos do cruzamento de fêmeas F1 (LD x LW) com machos Duroc e/ou sintéticos, desmamados aos 21 dias e alojados em uma sala-creche, equipada com 24 baias elevadas (1,2 x 1,2 × 0,8 metros), com piso parcialmente vazado ( $1 / 2$ plástico e $1 / 2$ madeira), equipadas com um bebedouro tipo nipple localizado na parte posterior das baias e um comedouro semi-automático instalado na porção lateral das baias. Para provimento de calor suplementar foram instaladas sobre cada baia uma lâmpada incandescente de 150w. A aeração interna foi controlada por um sistema de cortinas plásticas, colocadas nas aberturas laterais do prédio.

O delineamento experimental utilizado foi o inteiramente casualizado, composto por dois tratamentos, doze repetições e quatro animais em cada repetição. Os tratamentos experimentais utilizados foram: dieta simples (DS) e dieta complexa (DC). As dietas foram isonutritivas, elaboradas segundo tabela de exigências nutricionais, NRC (1988), contendo 21\% proteína bruta (PB) - 3.500kcal ED/kg; 20\% PB - 3.500kcal $\mathrm{ED} / \mathrm{kg}$ e $18 \% \mathrm{~PB}-3.500 \mathrm{kcal} \mathrm{ED} / \mathrm{kg}$, nas fases préinicial, inicial I e inicial II, sendo fornecidas nas proporções de $5 \mathrm{~kg}, 5 \mathrm{~kg}$ e ad libitum para cada animal, respectivamente. A composição das dietas é apresentada na tabela 1. A dieta simples foi compostas basicamente por farelo de soja, quirera de arroz, premix vitamínico e mineral, fosfato bicálcico, calcário, óleo de soja e sal. Já a dieta complexa, além dos ingredientes citados anteriormente, apresentou a inclusão de sucedâneo lácteo a base de leite em pó, nas proporções de 20, 10 e $0 \%$, nas fases pré-inicial, inicial I e inicial II, respectivamente. A fase experimental teve duração de 42 dias (dos 21 aos 63 dias de idade), na qual os animais foram pesados em intervalos de 14 dias, respeitando-se um jejum prévio de sólidos de 12 horas.

As variáveis estudadas foram o consumo de ração (a quantidade de ração fornecida foi medida diariamente e, no final de cada período, foi procedida a totalização subtraindo dos restos presentes nos comedouros), o ganho de peso (foi 
Tabela 1 - Composição das dietas experimentais de acordo com as fases criatórias.

\begin{tabular}{lccccc}
\hline & \multicolumn{5}{c}{ Fases } \\
\cline { 2 - 6 } Ingredientes (\%) & \multicolumn{2}{c}{ Pré-inicial } & Inicial I & Inicial II \\
\cline { 2 - 6 } & DS & DC & DS & DC & DS \\
\hline Farelo de Soja & 37,25 & 28,90 & 31,40 & 27,68 & 29,89 \\
Quirera de Arroz & 49,30 & 38,99 & 60,42 & 54,83 & 62,80 \\
Suiline & 00 & 20,00 & 00 & 10,00 & 00 \\
Óleo de Soja & 7,10 & 5,79 & 2,28 & 1,61 & 00 \\
Fosfato Bicálcico & 2,30 & 2,19 & 2,01 & 1,94 & 2,05 \\
Calcário & 0,54 & 0,66 & 0,42 & 0,47 & 1,79 \\
Premix & 3,00 & 3,00 & 3,00 & 3,00 & 3,00 \\
Sal & 0,40 & 0,40 & 0,40 & 0,40 & 0,40 \\
Acidificante/Inerte & 0,065 & 0,065 & 0,065 & 0,065 & 0,065 \\
Total & 100 & 100 & 100 & 100 & 100 \\
\hline
\end{tabular}

DS $=$ Dieta simples

$\mathrm{DC}=$ Dieta complexa

medido aos 14, 28 e aos 42 dias), a conversão alimentar dos animais (obtida pelo quociente entre o consumo e o ganho de peso) e a ocorrência de diarréia (medida através de escores realizados diariamente durante a parte da tarde). Os dados obtidos foram submetidos à análise de variância e teste de Tukey utilizando-se o pacote estatístico SAS (1993).

\section{RESULTADOS E DISCUSSÃO}

Os resultados referentes ao peso vivo dos animais nos diferentes períodos encontram-se na tabela 2. Não houve diferença estatística para esta variável em nenhum dos períodos estudados. Resultados contrários foram encontrados por EFIRD et al. (1982), que usando dietas similares ao deste trabalho, verificaram maior peso vivo aos 28 e 35 dias de idade, para animais que recebiam dieta à base de sucedâneo lácteo, porém em ambas idades os pesos vivos dos animais foram inferiores ao deste trabalho.

Conforme a tabela 3 , verificou-se um maior consumo de ração $(\mathrm{P}<0,01)$ para dieta complexa em relação a simples, na primeira fase, sendo de 5,161 e 4,537kg, respectivamente. $\mathrm{Na}$ segunda fase o consumo da dieta complexa foi levemente inferior ao da simples e o inverso ocorreu na terceira fase, onde o consumo da dieta complexa foi levemente superior ao da simples, porém não se verificou diferença significativa nas duas últimas fases. O maior consumo de ração para dieta complexa, na primeira fase, possivelmente, está relacionado com a maior inclusão de sucedâneo lácteo $(20 \%)$, uma vez que este apresenta melhor palatabilidade e digestibilidade, consequentemente maior velocidade de passagem pelo trato gastrintestinal dos leitões. Corroborando com este trabalho vários pesquisadores, como OKAI et al. (1976), ARMSTRONG \& CLAWSON (1980), EFIRT et al. (1982), GIESTING et al. (1991) e ETHERIDGE $\boldsymbol{e t}$ al. (1984), notaram que a adição de altos níveis de leite em pó em dietas para leitões após o desmame tendem a aumentar o consumo de ração. Também ALEE (1985) conduziu experimentos para estudar o efeito de dietas simples (milho + soja) versus dietas complexas (milho, soja, aveia, açúcar, leite em pó desnatado, solúveis de peixe e levedura) sobre o desempenho de leitões desmamados aos 21 dias e verificaram que leitões alimentados com dietas complexas consumiram mais. No mesmo estudo, o autor mostra que a dieta complexa deve ser ministrada a leitões desmamados às três semanas por mais 10 dias após o desmame para obtenção de resultados satisfatórios.

Em estudos realizados por MEADE $\boldsymbol{e t}$ al. (1969 a, b) e CRENSHAW et al. (1986), que, testando dietas simples (milho-soja) e dietas complexas (milho, farelo de soja, farinha de peixe, leite em pó desnatado) com níveis de proteína bruta variando de 17 a $20 \%$, para leitões desmamados às três semanas de idade, não encontraram diferenças com relação ao consumo de ração. $O$ mesmo foi verificado por BALEY \& CALSON (1970), CARVALHO et al. (1999) e FERREIRA et al. (1999) que compararam dietas simples e complexas e constataram que o consumo de ração não diferiu estatisticamente para os dois tipos de dietas utilizadas.

$\mathrm{Na}$ tabela 4, estão expressos

$\mathrm{P} 1=$ Peso no final do primeiro período

$\mathrm{P} 2$ = Peso no final do segundo período

P3 = Peso no final do terceiro período

$\mathrm{S}=$ Desvio padrão os valores referentes ao ganho médio 
Tabela 3 - Valores médios e estatísticas referentes ao consumo de ração de leitões alimentados com dietas simples e complexas, na fase de creche.

\begin{tabular}{lcccccccc}
\hline Dietas & C1 & S & C2 & S & C3 & S & CT & S \\
\hline Complexa & $5,161^{\text {a }}$ & $\pm 0,429$ & 9,385 & $\pm 0,623$ & 14,343 & $\pm 1,080$ & 28,890 & $\pm 1,855$ \\
Simples & $4,537^{\mathrm{b}}$ & $\pm 0,339$ & 9,437 & $\pm 0,905$ & 13,796 & $\pm 1,605$ & 27,771 & $\pm 2,753$ \\
Média geral & 4,849 & $\pm 0,493$ & 9,411 & $\pm 0,739$ & 14,070 & $\pm 1,004$ & 28,330 & $\pm 2,038$ \\
F & 9,61 & & 0,03 & & 1,78 & & 1,810 & \\
P< & 0,005 & & 0,865 & & 0,197 & 0,193 & \\
CV $(\%)$ & 10,176 & & 7,853 & & 7,136 & 7,193 & \\
\hline
\end{tabular}

$\mathrm{C} 1$ = Consumo de ração no primeiro período

$\mathrm{C} 2$ = Consumo de ração no segundo período

C3 = Consumo de ração no terceiro período

CT = Consumo total de ração

$\mathrm{S}=$ Desvio padrão

diário de peso dos animais. Houve diferença significativa somente na primeira fase, onde as dietas complexas apresentaram um maior ganho $(\mathrm{P}<$ $0,05)$ em relação as simples, sendo de 0,223 e $0,192 \mathrm{~kg}$, respectivamente. Nas demais fases, o ganho foi similar. Resultados semelhantes foram encontrados por FALKOWSKI \& AHERNE (1984), EDMONDS et al. (1985) e BURNELL et al. (1988), que observaram melhora no ganho de peso, sendo que os melhores resultados foram obtidos nas fases iniciais, até $25 \mathrm{~kg}$ de peso vivo.

Os subprodutos do leite proporcionam bom desempenho aos leitões jovens, tanto em função da qualidade da proteína como da fração de carboidratos (lactose), mas a lactose parece ser o componente mais importante no caso do soro de leite (MAHAN, 1991). TOPLIS \& TIBLE (1994) em experimento com diferentes tipos de dietas obtiveram ganho de peso superior para dietas contendo leite em pó comparadas com as proteínas menos elaboradas da soja para leitões jovens. SOARES et $\boldsymbol{a l}$. (2000), em experimento realizado

Tabela 4 - Valores médios e estatísticas referentes ao ganho de peso médio diário de leitões alimentados com dietas simples e complexas, na fase de creche.

\begin{tabular}{lcccccccc}
\hline Dietas & GMD1 & S & GMD2 & S & GMD3 & S & GMDT & S \\
\hline Complexa & $0,223^{\mathrm{a}}$ & $\pm 0,025$ & 0,361 & $\pm 0,039$ & 0,552 & $\pm 0,043$ & 0,379 & $\pm 0,029$ \\
Simples & $0,192^{\mathrm{b}}$ & $\pm 0,033$ & 0,375 & $\pm 0,027$ & 0,520 & $\pm 0,093$ & 0,362 & $\pm 0,043$ \\
Média geral & 0,208 & $\pm 0,03$ & 0,368 & $\pm 0,033$ & 0,536 & $\pm 0,059$ & 0,371 & $\pm 0,033$ \\
F & 6,29 & & 1,00 & & 1,72 & & 1,400 & \\
P< & 0,02 & & 0,33 & & 0,204 & & 0,250 & \\
CV $(\%)$ & 14,489 & & 9,224 & & 11,173 & & 9,149 & \\
\hline
\end{tabular}

GMD1 = Ganho médio diário no primeiro período GMD2 = Ganho médio diário no segundo período GMD3 = Ganho médio diário no terceiro período GMDT $=$ Ganho médio diário total $\mathrm{S}=$ Desvio padrão com leitões desmamados aos 14 dias e alimentados com dietas à base de soja integral processada ou farelo de soja em substituição ao leite em pó verificaram maior ganho de peso $(\mathrm{P}$ $<0,05)$ dos 14 aos 35 dias e dos 14 aos 56 dias para os animais alimentados com dieta a base de leite em pó; já dos 36 aos 56 dias não houve diferença estatística.

Baseados nos trabalhos desenvolvidos por diversos autores, como CERA et al. (1998), TOKACH et al.(1989), MAHAN (1991) e MAHAN et al. (1993), pode-se afirmar que os subprodutos do leite são indispensáveis nas dietas iniciais de desmame e que os melhores níveis de inclusão variam de 10 a $35 \%$ dependendo da idade de desmame. NETO et al. (1996) conduziram um estudo com dietas simples (milho + farelo de soja + resíduo de bolacha) e semicomplexa (dieta simples + lactose), verificando que o tipo de dieta não exerceu influência sobre o desempenho dos leitões, dos 24 aos 65 dias de idade. Também KATZ et al. (1973) observaram a eficiência de utilização de rações simples e complexas para leitões de 5 semanas de idade e relataram que uma ração simples (milho + farelo de soja) proporciona desempenho de leitões jovens idêntico ao obtido com ração complexa (milho + cevada + farelo de soja + farinha de peixe + soro de leite seco).

$\mathrm{Na}$ tabela 5, são apresentados os valores médios referentes à conversão alimentar dos animais nos diferentes períodos. Para esta variável, os resultados foram similares e não diferiram significativamente em nenhum período. $\mathrm{O}$ contrário foi constatado por BALEY \& CALSON (1970), CARVALHO et al. (1999) e FERREIRA $\boldsymbol{e t}$ al. (1999). Já OKAI et al. (1976), EFIRD et al. (1982), FALKOWSKI \& AHERNE (1984), ALEE (1985), EDMONDS et al. (1985) e BURNELL $\boldsymbol{e t}$ al. (1988) que observaram melhora na conversão alimentar dos animais alimentados com dietas complexas.

\section{CONCLUSÕES}

Pelos resultados obtidos no presente experimento, pode observar-se que a) animais alimentados com dietas complexas apresentam um maior consumo de ração; b) maior ganho médio diário na primeira fase de creche e o tipo 
Tabela 5 - Valores médios e estatísticas referentes a conversão alimentar de leitões alimentados com dietas simples e complexas, na fase de creche.

\begin{tabular}{lcccccccc}
\hline Dietas & CA1 & S & CA2 & S & CA3 & S & CAT & S \\
\hline Complexa & 1,657 & $\pm 0,147$ & 1,868 & $\pm 0,154$ & 1,858 & $\pm 0,127$ & 1,816 & $\pm 0,07$ \\
Simples & 1,698 & $\pm 0,156$ & 1,799 & $\pm 0,130$ & 1,916 & $\pm 0,157$ & 1,827 & $\pm 0,08$ \\
Média geral & 1,677 & $\pm 0,153$ & 1,834 & $\pm 0,137$ & 1,887 & $\pm 0,137$ & 1,822 & $\pm 0,08$ \\
F & 0,42 & & 1,54 & & 1,08 & & 0,110 & \\
P< & 0,522 & & 0,228 & & 0,311 & & 0,747 & \\
CV $(\%)$ & 9,177 & & 7,509 & & 7,283 & & 7,193 & \\
\hline
\end{tabular}

CA1 = Conversão alimentar no primeiro período $\mathrm{CA} 2=$ Conversão alimentar no segundo período CA3 $=$ Conversão alimentar no terceiro período CAT $=$ Conversão alimentar total $\mathrm{S}=$ Desvio padrão

de dieta não influencia, no período total, o peso e a conversão alimentar dos leitões na fase de creche.

\section{REFERÊNCIAS BIBLIOGRÁFICAS}

ALEE, G.L. Nutrition of the weaned pigs. In: MARYLAND NUTRITION CONFERENCE FOR FEED MANUFACTURERS, 1985, Maryland. Anais... Maryland : Univer. Maryland, 1985. p.56.

ARMSTRONG, W.D.; CLAWSON, A.J. Nutrition and management of early weaned pigs: Effects of increased nutrient concentrations and (or) supplemental liquid feeding. Journal of Animal Science, v.50, p.376, 1980.

BALEY, H.S.; CALSON, W.E. Comparisons of simple and complex diets for baby pigs: effect of form of feed and of glucose addition. Journal of Animal Science, v.30, n.3, p.394-401, 1970 .

BURNELL, T.W.; GROMWELL, G.L.; STAHLY, T.S. Effects of dried whey and copper sulfate on the growth responses to organic acid in diets for wealing pigs. Journal of Animal Science, v.66, p.100, 1988.

CARVALHO, L.E. de; KRONKA, R.N.; THOMAZ, M.C., $\boldsymbol{e t}$ al. Níveis de proteína e tipos de dietas na fase inicial de leitões desmamados com alto peso e possíveis efeitos na fase de crescimento. In: REUNIÃO ANUAL DA SOCIEDADE BRASILEIRA DE ZOOTECNIA, 36, 1999, Porto Alegre, RS. Anais... Porto Alegre : SBZ, 1999. p.206.

CERA, K.R.; MAHAN, D.C.; REINHART, G.A. Effects of dietary dried whey and corn oil on weanhing pig performance, fat digestibility and nitrogen utilization. Journal of Animal Science, v.66, n.6, p.1438-1445, 1988.

CRENSHAW, T.D.; COOK, M.E.; COLE, J., et al. Effect of nutritional status, age at weaning and room temperature on growth and systemic immune response of wianinling pigs. Journal of Animal Science, v.63, n.6, p.1845-1853, 1986.

DRIZT, S.S., TOKACH, M.D., GOODBAND, R.D., $\boldsymbol{e}$ t $\boldsymbol{a l}$. The effect of weaning age on nursery pig feeding behavior and growth performance. In: AMERICAN ASSOCIATION OF SWINE PRACTITIONERS, 25, 1994, Omaha. Proceedings... [SI.:s.n.], 1994. p.194-211.

EDMONDS, M.S.; IZQUIERDO, O.A.; BAKER, D.H. Feed additives studies with newly weaned pigs: Efficacy of supplemental copper, antibiotics and organic acids. Journal of Animal Science, v.60, p.462, 1985.

EFIRD, R.C.; ARMSTRONG, W.D.; HERMAN, D.C. The development of digestive capacity in young pigs: Effects of weaning regimen and dietary treatment. Journal of Animal Science, v.55, p.1371, 1982 .

ETHERIDGE, R.D.; SEERLEY, R.W.; WYATT, R.D. The effect of diet on performance, digestibility, blood composition and internal microflora of weaned pigs. Journal of Animal Science, v.58, p.1396, 1984.

FALKOWSKI, J.F.; AHERNE, F.X. Fumaric and citric acid as feed additives in starter pig nutrition. Journal of Animal Science, v.60, p.1288, 1984.

FERREIRA, V.P. de A.; FERREIRA, A.S.; DONZELE, J.L., et al. Dietas para leitões em aleitamento e pós-desmame. In: REUNIÃO ANUAL DA SOCIEDADE BRASILEIRA DE ZOOTECNIA, 36, 1999. Porto Alegre, RS. Anais... Nutrição de Não Ruminantes. Porto Alegre : SBZ, 1999. p.210.

GIESTING, D.W.; ROOS, M.A.; EASTER, R.A. Evaluation of the effect of fumaric acid and sodium bicarbonate addition on performance of stArter pigs fed diets of differenct types. Journal of Animal Science, v.69, p.2489-2496, 1991.

KATZ, R.S.; BAKER, D.H.; SASSE, C.E., et al. Efficacy of supplemental lysine, methionine and ralled oats for weaning pigs fed a law-protein corn-soybean meal diet. Journal of Animal Science, v.37, p.1165-1168, 1973.

LUDKE, J.V.; BERTOL, T.M.; SCHEUERMANN, G.N. Manejo da alimentação. In: SOBESTIANSKY, J.; WENTZ, I.; SILVEIRA, P.R.S. da, et al. Suinocultura intensiva. Concórdia : CNPSA, 1998. Cap.4. p.66-90.

MAHAN, D.C. Efficacy of initial postweaning diet and supplemental coconut oil or soybean oil for weanling swine. Journal of Animal Science, v.69, n.4, p.1397-1402, 1991.

MAHAN, D.C.; CERA, K.R. Changes in intestinal morphology a major reason for the growth check following weaning. Pig news and Information, v.14, n.4, p.373, 1993.

MAHAN, D.C.; LEPINE, A.J. Effect of pig weaning and associated nursery feeding programs on subsequent performance to 105 kilograms body weight. Journal of Animal Science, v.69, n.4, p.1370-1378, 1991.

MAHAN, D.C.; EASTER, G.L.; CROMWELL, G.L., $\boldsymbol{e} \boldsymbol{t}$ al. Effect of dietary lysine levels formulated by altering the ratio of corn: soybean meal with or without dried whey and Llisine. $\mathrm{HCl}$ in diets for weanling pigs. Journal of Animal Science, v.71, n.7, p.1848-1852, 1993. 
MEADE, R.J.; VERDMEDAHL, L.D.; RUST, J.W., et al. Effects of protein content of the diet the young pig on rate and efficiency of gain during early development and subsequent to $23,5 \mathrm{~kg}$, and carcass characteristics and composition of lean tissue. Journal of Animal Science, v.29, n.4, p.463-477, 1969a.

MEADE, R.J.; VERDMEDAHL, L.D.; RUST, J.W., et al. Effects of protein content of the diet the young pig on rate and efficiency of gain during early development and subsequent to $23,5 \mathrm{~kg}$, and carcass characteristics and composition of lean tissue. Journal of Animal Science, v.29, n.4, p.463-477, 1969b.

NATIONAL RESEARCH COUNCIL - NRC. Nutrient requirements of domestic animals nutrient requeriments of swine. 9ed. rev. [S.I. Washington] : National Academy, 1988. 93p

NETO, M.A. da T.; BARBOSA, H.P.; SCHAMMASS, E.A Dietas e processamentos de ração para leitões desmamados aos 24 dias de idade - fase I e II. In: REUNIÃO ANUAL DA
SOCIEDADE BRASILEIRA DE ZOOTECNIA, 33, 1996. Fortaleza, CE. Anais... Nutrição de Não Ruminantes. Fortaleza : SBZ, 1996. V.4. p.99-101.

OKAI, D.B.; AHERNE, F.S.; HARDIN, R.T. Effects of creep and starter composition on feed intake and performance of woung pigs. Canada. Journal of Animal Science, v.56, p.573, 1976.

SAS/ STAT. User's Guide; version 6. 4ed. North Caroline SAS Institute, 1993. 1686p.

SOARES, J.L.; BONZELE, J.L.; OLIVEIRA, R.F.M. de, et al. Soja integral processada (fermentada e extrusada) e farelo de soja em substituição ao leite em pó em dietas de leitões desmamados aos 14 dias de idade. Revista Brasileira de Zootecnia, v.29, n.4, p.1153-1161, 2000.

TOKACH, M.D.; NELSSEN, J.L.; ALEE, G.L. Effect of protein and or carbohidrate fractions of dried whey on performance and nutrient digestibility of early weaned pigs. Journal of Animal Ciente, v.67, n.5, p.1307-1312, 1989.

TOPLIS, P.; TIBLE, S. Improvement of post-weaning intake of piglets explored. Feedstuffs, v.66, n.32, p.12-16, 1994. 